\title{
Emoções e sentimentos de mães na hospitalização de seus recém-nascidos
}

\author{
Mother's emotions in the hospitalization of their newborms \\ Emociones de madres durante la hospitalización de sus recién nacidos
}

\author{
Bianca de Fátima Ramos Souza \\ ORCID: https://orcid.org/0000-0002-5583-7751 \\ Universidade de Pernambuco, Brasil \\ E-mail: biancaramosouza@gmail.com \\ Maria Gabriella de Melo \\ ORCID: https://orcid.org/0000-0002-8644-5945 \\ Universidade de Pernambuco, Brasil \\ E-mail: gabriellamelo0911@gmail.com \\ João Henrique Barbosa Neto \\ ORCID: https://orcid.org/0000-0002-8794-2775 \\ Universidade Federal de Campina Grande, Brasil \\ E-mail: jhenriquebneto@gmail.com \\ Thalyta Roberta Silva Bastos \\ ORCID: https://orcid.org/0000-0002-9783-3927 \\ Universidade de Pernambuco, Brasil \\ E-mail: thalyta.bastos@ hotmail.com \\ Judith Victoria Castillo Mejia \\ ORCID: https://orcid.org/0000-0001-5257-6878 \\ Universidade de Pernambuco, Brasil \\ E-mail: iker07castillo@live.com \\ Brígida Maria Gonçalves de Melo Brandão \\ ORCID: https://orcid.org/0000-0002-2296-6688 \\ Universidade de Pernambuco, Brasil \\ E-mail: bri.melo@hotmail.com \\ Fátima Maria da Silva Abrão \\ ORCID: https://orcid.org/0000-0003-3254-2851 \\ Universidade de Pernambuco, Brasil \\ E-mail: abraofatima@gmail.com
}

\begin{abstract}
Resumo
Objetivo: Descrever as produções científicas que abordem as emoções e sentimentos de mães durante a internação de recém-nascidos em Unidades de Terapia Intensiva. Metodologia: revisão integrativa de literatura, realizada com recorte temporal de 2016 a 2020. Os resumos dos artigos foram lidos e avaliados, sendo selecionadas para a pesquisa as produções que atenderam aos critérios de busca previamente estabelecidos. Resultados: Inicialmente, foram encontrados dezesseis artigos, porém, após aplicação dos critérios de exclusão, a amostra final resultou em sete artigos. A análise dos dados possibilitou a classificação das publicações em categorias temáticas: categoria A: Confusão emocional; categoria B: rede de apoio e categoria C: espiritualidade. Conclusão: Conclui-se nesse estudo que, é importante a realização de trabalhos que visem entender os sentimentos e vivências de pessoas com familiares em internação, principalmente de mães e seus neonatos. Assim, tendo em vista as emoções dessa experiência, criar estratégias com o intuito de diminuir situações que causem medo e ansiedade.
\end{abstract}

Palavras-chave: Emoções; Mães; Recém-nascido; Unidades de Terapia Intensiva.

\begin{abstract}
Objective: To describe scientific productions that address the emotions and feelings of mothers during the hospitalization of newborns in Intensive Care Units. Methodology: integrative literature review, carried out with a time frame from 2016 to 2020. The abstracts of the articles were read and evaluated, and the productions that met the previously established search criteria were selected for the research. Results: Initially, sixteen articles were found, however, after applying the exclusion criteria, the final sample resulted in seven articles. Data analysis made it possible to classify publications into thematic categories: category A: Emotional confusion; category B: support network and category C: spirituality. Conclusion: It is concluded in this study that it is important to carry out works that aim to understand the feelings and experiences of people with family members in hospital, especially mothers and their newborns. Thus, in view of the emotions of this experience, create strategies in order to reduce situations that cause fear and anxiety.
\end{abstract}

Keywords: Emotions; Mothers; Newborn; Intensive Care Units. 


\begin{abstract}
Resumen
Objetivo: Describir producciones científicas que aborden las emociones y sentimientos de las madres durante la hospitalización de recién nacidos en las Unidades de Cuidados Intensivos. Metodología: revisión integradora de la literatura, realizada con un período de tiempo de 2016 a 2020. Se leyeron y evaluaron los resúmenes de los artículos y se seleccionaron para la investigación las producciones que cumplieron con los criterios de búsqueda previamente establecidos. Resultados: Inicialmente se encontraron dieciséis artículos, sin embargo, luego de aplicar los criterios de exclusión, la muestra final resultó en siete artículos. El análisis de datos permitió clasificar las publicaciones en categorías temáticas: categoría A: confusión emocional; categoría B: red de apoyo y categoría C: espiritualidad. Conclusión: En este estudio se concluye que es importante realizar trabajos que tengan como objetivo comprender los sentimientos y vivencias de las personas con familiares en el hospital, especialmente las madres y sus recién nacidos. Así, ante las emociones de esta experiencia, crear estrategias con el fin de reducir situaciones que provocan miedo y ansiedad.
\end{abstract}

Palabras clave: Emociones; Madres; Recién nacido; Unidades de Cuidados Intensivos.

\title{
1. Introdução
}

A Organização Mundial da Saúde (OMS, 2018) considera a prematuridade como um problema a nível mundial, principalmente por sua relação com a mortalidade neonatal. Em casos de parto pré-termo ou de recém-nascidos (RN) não saudáveis, é recorrente a incidência de internações em Unidades de Terapia Intensiva (UTIs), e na rotina da hospitalização, muitas vezes a mãe não pode estar com seu bebê durante todos os momentos, diante da execução de procedimentos invasivos, do espaço físico limitado, das medidas de prevenção de infecção hospitalar e de recursos humanos insuficientes, acarretando transtornos emocionais nessas mães e também, por vezes, no próprio neonato (Carvalho; Pereira, 2017; Soares, et al., 2016).

É sabido que desde a gravidez a mulher começa a estabelecer um relacionamento afetivo com seu bebê, e passa a se identificar profundamente e ter sentimentos positivos sobre ele (Chavtal; Vasconcellos; Rivoredo; Turato, 2017). O sentimento da mãe se fortifica concomitantemente ao desenvolvimento da gestação; ao perceber alterações no seu corpo e os movimentos do feto em seu ventre, ao viver a expectativa do nascimento e no anseio por ter o filho em seus braços.

O feto no útero, além de receber da mãe toda fonte de vida, é capaz de identificar os sentimentos vividos por ela mediante alterações fisiológicas ocorridas no organismo em momentos de forte emoção. Durante toda a gestação, a mãe constrói imagens, sonhos e esperanças ao redor deste "ser" que é imaginado saudável, ativo e perfeito, e o nascimento de um RN enfermo, prematuro, pequeno e frágil pode desfazer todas essas expectativas (Santos; Teixeira, 2017).

Nesse contexto, com o decorrer do tempo, a mãe experimenta conflitos entre o medo da morte e a esperança da vida, vivenciando dias de melhoras e de pioras relacionadas à saúde do neonato. O estresse por vivenciar situações onde presenciam a vulnerabilidade de seus filhos e a ansiedade pela alta se faz constante, e para aquelas que assistem às altas de outras mães, a dor de ainda terem seus filhos sob cuidados da equipe de saúde se sobressai à esperança de alcançarem a mesma situação um dia (Kegler, et al., 2019; Soares, et al., 2016).

Atrelado a isso, sabe-se que as mães lidam de maneiras divergentes com a dúvida da morte ou da vida, da piora ou da melhora e com a ansiedade da espera, o que juntamente com o desconhecimento das condutas terapêuticas e dos equipamentos utilizados e com a imprevisibilidade do prognóstico promovem uma experiência desagradável no momento pós-parto. Por isso é necessário ter conhecimento das particularidades enfrentadas nesse momento delicado para a promoção de um cuidado adequado e direcionado a essas mulheres. Dessa forma, este artigo tem como objetivo descrever as produções científicas que abordem as emoções e sentimentos de mães durante a internação de recém-nascidos em Unidade de Terapia Intensiva.

\section{Metodologia}

Trata-se de uma revisão integrativa da literatura com uma análise qualitativa e descritiva dos estudos encontrados em bases de dados indexadas. Foram utilizadas seis fases para a elaboração da revisão: identificação do problema; estabelecimento de critérios de inclusão e exclusão; definição das informações a serem extraídas; avaliação dos resultados; interpretação dos 
resultados - e, por fim, apresentação dos estudos selecionados (Sousa; Marques-Vieira; Severino; Antunes, 2017; Pereira, et al. 2018).

A priori, o primeiro estágio buscou atentar para uma problemática que se faz presente no país atualmente, identificando um objetivo e as palavras-chave que retratam o tema da pesquisa. Para o desenvolvimento do estudo, todos os estágios subsequentes utilizaram a seguinte pergunta norteadora como princípio: "Como a reação emocional de genitoras frente à hospitalização dos seus neonatos foi abordada nas produções científicas em periódicos nacionais on-line no período de 2016 a 2020 ?".

A partir dessa identificação, partiu-se para a busca nas plataformas Descritores em Ciências da Saúde (DeCS) pelos termos acurados que remetessem ao escopo do estudo. Como resultado, obtiveram-se os descritores "Emoções", "Mães", "Recém nascidos" " "Unidade de Terapia Intensiva", utilizando também o operador booleano "AND” na estratégia de busca. A plataforma utilizada para a pesquisa foi o Portal Regional da Biblioteca Virtual em Saúde (BVS), que contém as principais bases de dados das ciências da saúde a nível global indexadas, como MEDLINE (Medical Literature Analysis and Retrieval System Online), LILACS (Literatura Latino-Americana e do Caribe em Ciências da Saúde) e BDENF (Banco de Dados em Enfermagem).

Na segunda fase, estabeleceram-se como critérios de inclusão para seleção da amostra os artigos completos publicados nos últimos quatro anos, no idioma português. Foram excluídas teses, dissertações, monografias e artigos duplicados ou incompletos. Assim foi procedido para que se pudessem trazer resultados que aproximassem a pesquisa tanto ao tema quanto à realidade vivenciada nos últimos anos. A pesquisa foi realizada em setembro de $2020 \mathrm{e}$, à medida que foram adicionados, os filtros mencionados resultaram em uma amostra com 16 artigos.

As fases três e quatro se deram pela análise criteriosa dos artigos encontrados, e, para tal, o quarto estágio se subdividiu em três etapas: a primeira consistiu em uma leitura atenta ao título de todos os artigos identificados e a partir dela a exclusão dos estudos que não tinham afinidade com o objetivo do estudo; a segunda etapa tratou da leitura dos resumos dos artigos remanescentes, também culminando na eliminação daqueles que não atendiam ao escopo da pesquisa e, por fim, a etapa final do estágio foi a leitura integral do texto, através da qual se estabeleceu se ele respondia ou não à pergunta norteadora central da pesquisa, tendo isso como critério para sua inclusão ou exclusão.

A partir das três etapas do quarto estágio, os pesquisadores puderam edificar um instrumento sob a forma de uma tabela para registrar os resultados obtidos na intenção de se criarem categorias sistemáticas a fim de distinguir padrões, temas, variações e propriedades entre os estudos selecionados, subsidiando a quinta fase. Optou-se pela relevância das seguintes particularidades de cada estudo selecionado: Identificação do estudo (título do periódico, ano de publicação, autoria, título da pesquisa, base de dados ou biblioteca virtual); características metodológicas do estudo (objetivo e métodos); e avaliação dos resultados encontrados (resultados e conclusões).

Na sexta e última fase, através da análise de conteúdo, a discussão se realizou de forma contextualizada, com identificação de categorias temáticas coerentes agrupados por semelhança, formando assim a revisão integrativa. Salienta-se que a análise crítica da amostra levou em consideração as recomendações da ferramenta PRISMA (Preferred Reporting Items for Systematic Reviews and Meta-Analysis) (Galvão; Parsani, 2015).

\section{Resultados}

Na busca inicial, foram encontrados 16 artigos e, após a exclusão de 1 dissertação de mestrado, 1 artigo duplicado e 7 estudos que não responderam à pergunta norteadora, obteve-se como amostra final 7 artigos. Dentre os 7 artigos encontrados, 4 $(57,14 \%)$ estavam indexados no BDENF, $2(28,6 \%)$ na LILACS e $1(14,26 \%)$ na Scientific Electronic Library Online (SciELO). O ano de 2018 expressou maior número de publicações com três artigos; em 2015, 2017,2019 e 2020, houveram uma publicação, respectivamente. A Figura 1 sintetiza o delineamento metodológico percorrido por meio da estratégia PRISMA. 
Figura 1. Fluxograma PRISMA de artigos encontrados na Revisão Integrativa de Literatura com os descritores: "Emoções", “Mães", "Recém nascidos" e "Unidades de Terapia Intensiva” no portal da BVS. Brasil, 2020.

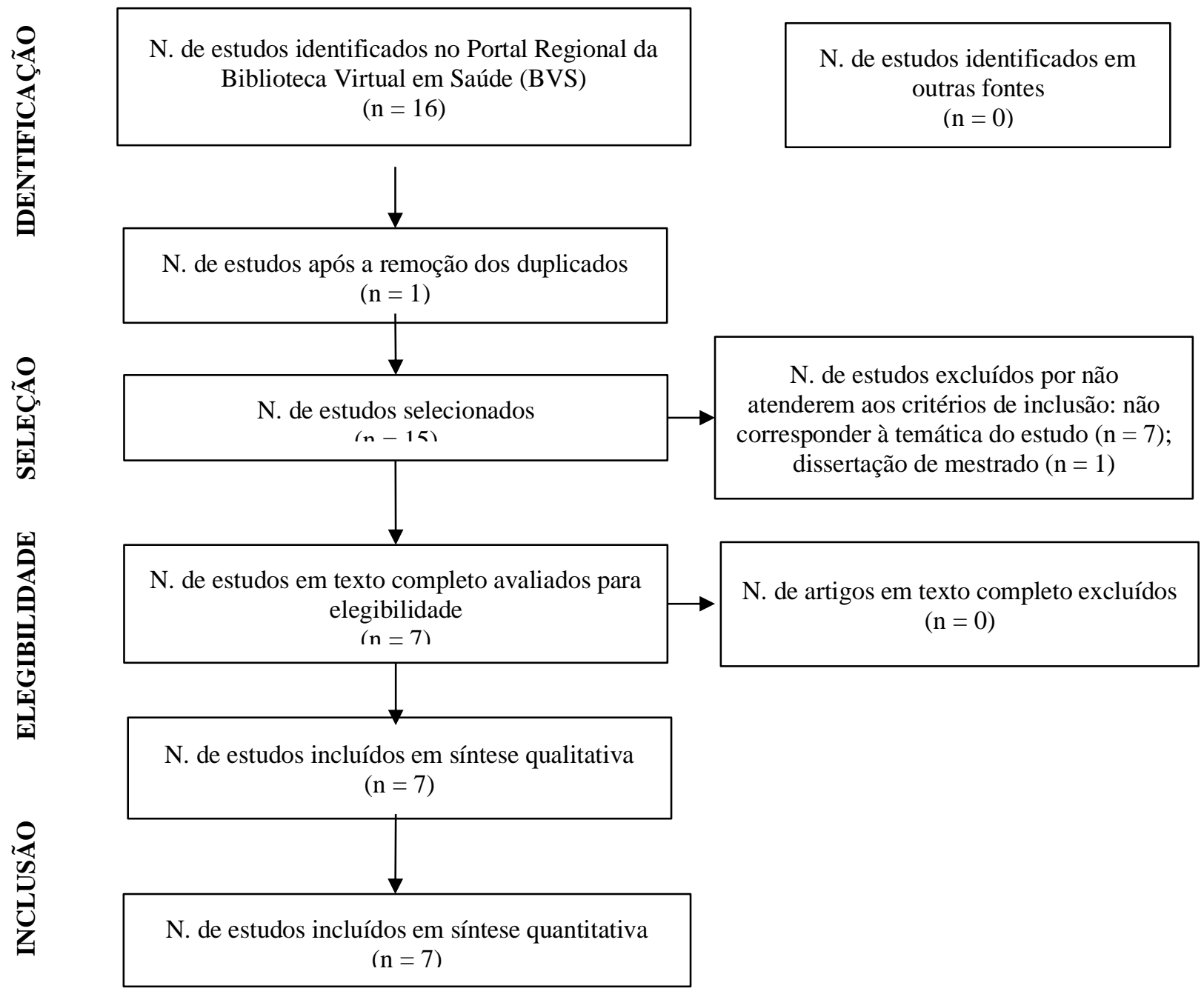

Fonte: Autores.

Observa-se que o decurso metodológico seguiu-se a priori por meio da identificação, seguida da seleção e da aplicação dos fatores de elegibilidade e findou na inclusão de sete estudos na amostra final. O Quadro 1, a seguir, lista e detalha os artigos incluídos na amostra desta revisão. 
Quadro 1. Distribuição dos artigos incluídos na pesquisa segundo número do artigo, periódico, ano, autoria, título, base de dados ou biblioteca virtual, objetivo e métodos, 2021.

\begin{tabular}{|c|c|c|c|c|}
\hline $\mathbf{N}^{\mathbf{o}}$ & Periódico, ano e autoria & $\begin{array}{c}\text { Título e base de dados } \\
\text { ou biblioteca virtual }\end{array}$ & Objetivos & $\begin{array}{c}\text { Métodos e nível de evidência } \\
\text { (NE) }\end{array}$ \\
\hline 01 & $\begin{array}{l}\text { Revista Mineira de } \\
\text { Enfermagem, 2020; } \\
\text { Fermino V., et al. }\end{array}$ & $\begin{array}{l}\text { Sentimentos paternos } \\
\text { acerca da hospitalização } \\
\text { do filho em Unidade de } \\
\text { Internação Neonatal; } \\
\text { LILACS. }\end{array}$ & $\begin{array}{l}\text { Descrever os sentimentos } \\
\text { paternos acerca da } \\
\text { hospitalização do filho em } \\
\text { unidade de terapia intensiva } \\
\text { neonatal. }\end{array}$ & $\begin{array}{l}\text { Estudo exploratório descritivo, } \\
\text { desenvolvido em uma unidade } \\
\text { neonatal de um hospital público } \\
\text { de ensino. Os sujeitos foram } \\
\text { pais de recém-nascidos } \\
\text { hospitalizados. }\end{array}$ \\
\hline 02 & $\begin{array}{l}\text { Revista Psicologia em } \\
\text { estudos, 2019; } \\
\text { Lima L. G. \& Smeha L. } \\
\text { N. }\end{array}$ & $\begin{array}{l}\text { Experiência da } \\
\text { maternidade diante da } \\
\text { internação do bebê em } \\
\text { UTI: uma monta russa de } \\
\text { sentimentos; } \\
\text { SciELO. }\end{array}$ & $\begin{array}{l}\text { Conhecer a experiência das } \\
\text { mães durante a } \\
\text { hospitalização de seus } \\
\text { bebês em uma Unidade de } \\
\text { Terapia Intensiva do } \\
\text { interior do Rio Grande do } \\
\text { Sul. }\end{array}$ & $\begin{array}{l}\text { Estudo qualitativo exploratório } \\
\text { que possibilita maior } \\
\text { aproximação com o cotidiano e } \\
\text { as experiências vividas pelos } \\
\text { próprios sujeitos. }\end{array}$ \\
\hline 03 & $\begin{array}{l}\text { REUOL, 2018; } \\
\text { Almeida C. R., et al. }\end{array}$ & $\begin{array}{l}\text { Cotidiano de mães } \\
\text { acompanhantes na } \\
\text { Unidade de Terapia } \\
\text { Intensiva Neonatal; } \\
\text { BDENF.. }\end{array}$ & $\begin{array}{l}\text { Analisar o cotidiano das } \\
\text { mães acompanhantes cujos } \\
\text { filhos estão internados na } \\
\text { Unidade de Terapia } \\
\text { Intensiva Neonatal. }\end{array}$ & $\begin{array}{l}\text { Estudo qualitativo, } \\
\text { exploratório, realizado na Casa } \\
\text { da Puérpera de uma } \\
\text { maternidade pública. Dados } \\
\text { produzidos por meio de } \\
\text { entrevista semiestruturada. }\end{array}$ \\
\hline 04 & $\begin{array}{l}\text { REUOL, 2018; } \\
\text { Lelis B. D. B., et al. }\end{array}$ & $\begin{array}{l}\text { Acolhimento materno no } \\
\text { contexto da } \\
\text { prematuridade; } \\
\text { BDENF. }\end{array}$ & $\begin{array}{l}\text { Analisar o acolhimento às } \\
\text { mães de recém-nascidos } \\
\text { pré-termo (RNPT) } \\
\text { hospitalizados nos } \\
\text { ambientes de cuidados de } \\
\text { um Hospital Amigo da } \\
\text { Criança. }\end{array}$ & $\begin{array}{l}\text { Estudo qualitativo e } \\
\text { exploratório pautado no } \\
\text { conceito de humanização a } \\
\text { partir de entrevistas } \\
\text { semiestruturadas gravadas com } \\
\text { as mães. }\end{array}$ \\
\hline 05 & $\begin{array}{l}\text { Psicologia, ciência e } \\
\text { profissão, 2018; } \\
\text { Zanfolim L. C., et al. }\end{array}$ & $\begin{array}{l}\text { Dificuldades Vivenciadas } \\
\text { pelas Mães na } \\
\text { Hospitalização de seus } \\
\text { Bebês em Unidades } \\
\text { Neonatais; } \\
\text { LILACS. }\end{array}$ & $\begin{array}{l}\text { Descrever os sentimentos e } \\
\text { dificuldades que as mães } \\
\text { vivenciam durante a } \\
\text { hospitalização do seu filho. }\end{array}$ & $\begin{array}{l}\text { Estudo qualitativo, com } \\
\text { abordagem de pesquisa-ação, } \\
\text { tendo como cenário o setor de } \\
\text { Neonatologia do Hospital } \\
\text { Universitário da UFGD. }\end{array}$ \\
\hline 06 & $\begin{array}{l}\text { Revista Baiana de } \\
\text { Enfermagem, 2017; } \\
\text { Bezerra M. J., et al. }\end{array}$ & $\begin{array}{l}\text { Percepção de mães de } \\
\text { recém-nascidos } \\
\text { prematuros hospitalizados } \\
\text { acerca da amamentação; } \\
\text { BDENF }\end{array}$ & $\begin{array}{l}\text { Compreender como as mães } \\
\text { percebem o processo de } \\
\text { amamentação de seu filho } \\
\text { prematuro hospitalizado na } \\
\text { Unidade de Terapia } \\
\text { Intensiva Neonatal. }\end{array}$ & $\begin{array}{l}\text { Estudo descritivo- exploratório } \\
\text { qualitativo realizado em uma } \\
\text { cidade do interior do Ceará, } \\
\text { Brasil. }\end{array}$ \\
\hline 07 & $\begin{array}{l}\text { Revista de pesquisa } \\
\text { cuidado é fundamental } \\
\text { online, 2015; } \\
\text { Vieira J. M. F., et al. }\end{array}$ & $\begin{array}{l}\text { Vivências de mães de } \\
\text { bebês prematuros no } \\
\text { contexto da } \\
\text { espiritualidade } \\
\text { BDENF. }\end{array}$ & $\begin{array}{l}\text { Compreender como mães } \\
\text { de bebês prematuros } \\
\text { percebem a relação entre } \\
\text { saúde e espiritualidade } \\
\text { e seus benefícios diante da } \\
\text { gravidade do quadro de } \\
\text { saúde de seus filhos. }\end{array}$ & $\begin{array}{l}\text { Pesquisa qualitativa } \\
\text { realizada com } 32 \text { mães, cujos } \\
\text { filhos estavam internados em } \\
\text { uma Unidade de Terapia } \\
\text { Intensiva Neonatal de } \\
\text { uma Maternidade Escola em } \\
\text { Natal/RN/Brasil. }\end{array}$ \\
\hline
\end{tabular}

Fonte: Autores.

O Quadro 1 detalha as informações pertinentes relacionadas aos sete artigos que compuseram a amostra desta revisão. De acordo com os resultados e conclusões de cada publicação, a análise dos dados possibilitou a classificação das publicações 
em três categorias temáticas, resultando 3 artigos na categoria A: Confusão emocional; 2 artigos na categoria B: rede de apoio e 2 artigos na categoria $\mathrm{C}$ : espiritualidade.

\section{Discussão}

\section{Categoria A: Confusão emocional}

Os artigos incluídos nessa categoria abordam o medo e a angústia do que poderá acontecer, principalmente quando se trata do medo de perder o recém-nascido (Fermino, et al., 2020; Lima; Smeha, 2019; Rolim, et al., 2016). A separação súbita é um dos fatores que geram esse sentimento, pois a alta materna não associada à alta do bebê provoca na mãe medo e dor, uma vez que o desejo de levar o filho para casa - seu ambiente acolhedor e conhecido - é concebido desde o momento da gestação, atravessado de sonhos e fantasias. Cabe salientar ainda que no período puerperal há uma alteração emocional, essencial e provisória que permite às mães ter uma ligação intensamente ao recém-nascido, adaptando-se a ele e buscando atender todas as suas necessidades básicas (Lima; Smeha, 2019).

Além disso, a possível hospitalização prolongada da genitora pode implicar em frustrações, pois a mesma esperava ter um filho saudável que pudesse receber alta hospitalar sem intercorrência, retornando ao domicílio com ela (Lelis, et al., 2018). A decisão de permanecer para acompanhar o filho hospitalizado está ligada ao desejo de cumprir o papel de mãe que muitas vezes é inerente a ela. Essa necessidade de se fazer presente constantemente representa a ligação de afeto construída durante a gestação, o que não lhes permitem deixar o hospital sem levar seus filhos nos braços (Araújo; Rodrigues, 2017).

As mães acompanhantes vivenciam desafios na tentativa de se adaptar ao ambiente hospitalar, considerado um espaço novo, diferente do seu lar, que materializa a vivência do adoecimento e representa o deixar de viver o dia a dia habitual (Almeida, et al., 2016). Tal situação fica ainda mais delicada quando as mães possuem outros filhos, pois devido à sua ausência em casa $\mathrm{e}$ à necessidade de permanecer no hospital, essas mulheres acabam transferindo para outros membros da família a responsabilidade de cuidar dos seus próprios filhos, o que gera sentimento de negligenciamento do cuidado materno (Souza et al., 2018).

\section{Categoria B: Rede de Apoio}

A análise possibilitou incluir nesta categoria dois artigos que tratavam em seus resultados e conclusões sobre uma boa rede de apoio dos familiares, amigos e profissionais de saúde que as mães receberam, ressaltando a importância de atitudes e iniciativas nesse sentido para essa fase delicada do momento pós-parto (Lelis, et al., 2018; Zanfolim; Cerchiari; Ganassin, 2018).

O apoio familiar foi visto como pilar fundamental, capaz de sustentar e de renovar as forças das mulheres para dar continuidade à batalha pela recuperação de seus filhos. Estudos também mostram que a família representa um suporte emocional, espiritual e até financeiro para essas mães, constituindo-se um apoio importante para lidar com as situações adversas que a hospitalização provoca (Molina; Higarashi; Marcon, 2016). Um ambiente familiar saudável e harmonioso entre seus membros possibilita a compreensão das dificuldades vivenciadas e a participação nos cuidados de familiares em variadas situações assistenciais (Morais; Quirino; Camargo, 2017).

Um dos artigos elencou também, a importância da Casa da Gestantes (CG), que é um espaço de permanência para mulheres que têm filhos internados. Na CG, as mães encontraram acolhimento físico e emocional com as outras mães colegas de quarto, por estarem vivenciando a mesma situação e assim, provocam uma ajuda mútua, estabelecendo novas amizades e troca de experiências excepcionais para o enfrentamento da situação de vulnerabilidade emocional vivenciada (Lelis et al., 2018). Ademais, a visita e preocupação das amizades anteriores à hospitalização se tornou benéfica para as mães, uma vez que, muitas não receberam apoio de seus familiares (Figueiredo, et al., 2016).

Os profissionais de saúde, de modo multiprofissional, por sua vez, eram os que estavam mais próximos neste período de internação. Estudo revelou que as mães acompanhantes consideraram a equipe de saúde como um suporte, pois foram 
acolhidas desde antes do nascimento e ao longo da hospitalização do filho. Esse acolhimento se deu sob a forma de orientações, do acompanhamento especializado, suprindo as demandas assistenciais do binômio mãe-bebê e, assim, reduzindo ansiedade e promovendo bem-estar e conforto (Oliveira, et al., 2016).

A atuação do psicólogo é essencial nesse momento, porém, é importante ressaltar que toda a equipe multiprofissional envolvida no cuidado ao RN precisa se sentir responsável em acolher essa mãe e percebê-la em suas individualidades (Almeida, et al., 2018). O apoio psicossocial da equipe de enfermagem, por sua vez, é tão importante quanto o procedimento técnico voltado às alterações fisiológicas porque este nem sempre promove resultados eficazes diante de situações de estresse. A essência do cuidar humano é entendida e compreendida ao ver, sentir e pela escuta às necessidades do recém-nascido e da família como um todo. Com isso, a enfermagem possui a responsabilidade de envolver os familiares, centrando-se na figura dos pais e no cuidado especial às mães (Bassi, et al., 2017).

Entretanto, alguns dos artigos abordaram que nem sempre os profissionais de saúde foram bem preparados para lidar com a situação emocional das famílias, agindo com falta de empatia e desprezo (Bassi, et al., 2017). Dessa forma, é necessária uma preparação desde a formação, onde as instituições de ensino e universidades desde o princípio possam incentivar e estimular a empatia e a humanização da assistência da enfermagem, para que assim, sejam formados profissionais cada vez mais compromissados, empáticos e que realizem atendimento humanizado nos diferentes níveis de serviços.

\section{Categoria C: Espiritualidade}

Por fim, nesta categoria foram abordados dois artigos que ressaltaram a experiência com Deus, de acordo, com suas crenças, sendo a esperança e a fé estratégias de enfrentamento (Almeida, et al., 2018; Vieira, et al., 2018).

Perante a complexidade da situação, a crença é uma forma de alcançar a salvação, seja qual for o rito, a religião ou a cultura daquele que crê. Para estas mães, se apegar a um ser superior é uma maneira de se sentirem encorajadas e resistir diante do que vivenciam e da situação que enfrentam. Acreditar em algo superior traz esperanças, e com elas novas expectativas, uma maneira culturalmente aceita de passar por uma provação, acreditando que a fé dos homens é capaz de modificar uma realidade (Vieira, et al., 2018).

Dentro desse processo de hospitalização, é perceptível a importância e influência da espiritualidade. Diante dessa vivência, comumente se busca receber ajuda espiritual, sendo que aqueles que acreditam espiritualidade ou seguem as práticas de alguma religião, apresentam outra postura ante a doença e suas dificuldades (Gooding, et al., 2017).

Os artigos trouxeram que a oração foi incluída no tratamento em saúde, pois pode propiciar conforto, bem-estar espiritual, confiança e apoio, além de fortalecer a relação médico-usuário. A partir desse contexto, entende-se a importância da oração como estratégia de enfrentamento diante da enfermidade do filho. A oração quando realizada em grupos de autoajuda funciona como apoio, fortalecendo a fé dos participantes (Tavares, et al., 2018). Além disso, a simples troca de experiências sobre utilização da oração, os benefícios alcançados e o compartilhamento das dificuldades no plano da espiritualidade fazem com que os membros sintam que não estão isolados.

\section{Conclusão}

Diante do exposto, pôde-se perceber que a internação do bebê gera na mãe sentimentos como culpa, medo, angústia e, principalmente, tristeza diante da incerteza da sobrevivência do recém-nascido. Ainda foi possível detectar como a prematuridade suscita nas mães um sentimento de perda, considerando que sua gestação foi interrompida e ela não teve o tempo necessário para se preparar para essa nova realidade.

Esta revisão permitiu compreender como a família é uma rede de apoio essencial para pais e mães que têm seus filhos internados, além disso, como a vinculação entre mãe e recém-nascido pode ser comprometida durante o período de internação 
do neonato, fator que traduz que a rotina dentro do internamento é um forte agente de interferência no vínculo mãe-filho.

Mesmo quando não ocorre esse suporte por parte da família, pôde-se perceber o papel positivo da construção de vínculos com pessoas fora da família, onde seja possível trocar experiências e dessa forma gerar um conforto emocional maior nessas mães.

Além disso, foi visto como método que influencia positivamente na vivência dessa situação, o uso da espiritualidade como fator fortalecedor. Esta simples e acessível estratégia pode ser estimulada e lembrada a essas mães, porém mantendo sempre o completo respeito às mais diversificadas religiões e crenças.

Os resultados do presente estudo contribuem para o planejamento de ações pelos profissionais de saúde, que podem se empenhar para minimizar as situações estressantes, especialmente as que envolvem a alteração do papel parental, de forma que eles possam ser incluídos nas práticas sempre que for possível e não venha a trazer riscos. Além disso, acredita-se que o desenvolvimento deste estudo trará também uma reflexão nos profissionais de saúde acerca das suas práticas assistenciais. É de suma importância a realização de trabalhos como este que visem entender emoções e vivências de pessoas que têm familiares em internação, principalmente quando tratam-se de mães e seus filhos que acabaram de nascer. Assim, tendo em vista os enormes movimentos emocionais que viver essa experiência pode causar, é também papel dos profissionais de saúde desenvolver estratégias para manejar e tentar fortalecer essa família buscando diminuir situações que causem medo e ansiedade.

\section{Referências}

Almeida, C. R. V., Leite, I. C. O., Ferreira C. B. \& Corrêa V. A. C. (2016). The daily life in the context of illness and hospitalization: what say the accompanying mothers of children diagnosed with neoplasia? Cad Ter Ocup UFSCar (Online); 24(2):247-59.

Almeida, C. R., Morais, A. C., Lima K. D. F. \& Silva, A. C. O. C. (2018) Cotidiano de mães acompanhantes na unidade de terapia intensiva neonatal. Rev de Enfermagem UFPE Online:12(7):1949-56.

Araújo, B. B. M. \& Rodrigues, B. M. R. D. (2017). The accommodation for mothers of preterm newborns: a contribution to the Nursing action. Esc Anna Nery Rev Enferm; 14(2):284-92.

Bassil, K. L., Shah, P. S., Shah, V., Ye, X. Y., Lee, S. K., Jefferies, A. L., et al. (2017). Impact of late preterm and early term infants on Canadian neonatal intensive care units. Am J Perinatol;31(4):269-78.

Carvalho, L. S. \& Pereira, C. M. C. (2017) As reações psicológicas dos pais frente à hospitalização do bebê prematuro na UTI neonatal. Rev. SBPH, 20(2):101122 .

Chvatal, V. L. S., Vasconcellos, J. F. J., Rivoredo, C. R. S. \& Turato, E. R. (2017). Mecanismos de defesa utilizados por adolescentes com bebês prematuros em UTI neonatal. Rev. Paidéia, 27 (430-438).

Fermino, V., Mattos, K., Emidio, S. C. D. Castillo, A. M. C. M. \& Carmona, E. V. (2020). Sentimentos acerca da hospitalização do filho em Unidade de Internação Neonatal. Rev Min Enfermagem, 24-1280.

Figueiredo, S. V., Gomes, I. L. V., Pennafort, V. P. S., Monteiro, A. R. M. \& Figueiredo, J. V. (2016). Mothers' feelings attributed to the hospitalization of their child. Cogitare enferm (Online); 18(3):552-7.

Galvão, T. F. \& Pansani, T. S. A. (2015). Principais itens para relatar Revisões sistemáticas e Meta-análises: A recomendação PRISMA. Epidemiol. Serv. Saúde, Brasília, 24(2).

Gooding, J. S., Cooper, L. G., Blaine, A. I., Franck, L. S., Howse, J. L. \& Berns S. D. (2017). Family support and family-centered care in the neonatal intensive care unit: origins, advances, impact. Semin Perinatol;35(1):20-8.

Kegler, J. J., Neves, E. T., Silva, A. M., Jantsch, L. B., Bertoldo, C. S. \& Silva, J. H. (2019). Stress in Parents of Newborns in a Neonatal Intensive Care Unit. Esc Anna Nery, 23(1):1-6.

Lelis, B. D. B., Sousa, M. I., Mello, D. F., Wernet, M., Velozo, A. B. F. \& Leite, A. M. (2018). Acolhimento materno no contexto de prematuridade. Rev de Enfermagem UFPE Online, 12(6): 1563-9.

Lima, L. G. \& Smeha, L. N. (2019). Experiência da maternidade diante da internação do bebê em UTI: uma montanha russa de sentimentos. Rev psicologia em estudo: (24).

Molina, R. C. M., Higarashi, I. H. \& Marcon, S. S. (2016). Importance attributed to the social support network by mothers with children in an intensive care unit. Esc Anna Nery Rev Enferm;18(1):60- 67.

Morais, A. C., Quirino, M. D. \& Camargo C. L. (2017). Social support in caring for premature infants after hospital discharge. Rev eletrônica enf;14(3):654-62. 
Research, Society and Development, v. 10, n. 3, e45910313600, 2021

(CC BY 4.0) | ISSN 2525-3409 | DOI: http://dx.doi.org/10.33448/rsd-v10i3.13600

Oliveira, K., Veronez, M., Higarashi, I. H. \& Corrêa, D. A. P. (2016). Family life experience in the process of birth and hospitalization of a child in a neonatal ICU. Esc Anna Nery Rev Enferm;17(1):46- 53.

Pereira A. S. et al. (2018). Metodologia da pesquisa científica. UFSM. https://repositorio.ufsm.br/bitstream/handle/1/15824/Lic_Computacao_MetodologiaPesquisa-Cientifica.pdf?sequence $=1$

Rolim, K. M. C., Santiago, N. R., Vieira, T. L., Sancho, M. C., Frota, M. A., Boulard, H., et al. (2016). Imaginário de mães acerca da hospitalização do filho na unidade de terapia intensiva neonatal. Rev do Conselho Federal de Enfermagem, 7 (1): $42-46$.

Santos, D. S. S. \& Teixeira, E. C. (2017). Vínculo mãe-bebê no contexto da Unidade de Terapia Intensiva Neonatal: Revisão bibliográfica. Rev. Bras. de Saúde Funcional. 1(2), 8-19.

Soares, L. G., Rosa, N. M., Higarashi, I. H., Marcon, S. S. \& Molina, R. C. M. (2016). UTI pediátrica: o significado do cuidar na perspectiva da mãe. Rev online de pesquisa cuidado é fundamental, 814, 4965-4971.

Sousa, L. M. M., Marques-Vieira, C. M. A., Severino, S. S. P. \& Antunes, A. V. A metodologia da revisão integrativa da literatura em Enfermagem. Revista investigação em enfermagem - Novembro 2017: 17-26.

Souza, N. L., Araújo, A. C. P. F., Costa, I. C. C., Carvalho, J. B. L. \& Silva, M. L. C. (2018). Representations of mothers about the hospitalization of their premature child. Rev Bras Enferm, 62(5):729-733.

Tavares, M. M., Gomes, A. M. T., Barbosa, D. J., Rocha, J. C. C., Bernardes, M. M. R. \& Thiengo, P. C. S. (2018). Espiritualidade e religiosidade no cotidiano da Enfermagem Hospitalar. Rev. Enf. UFPE On-line; 12(4).

Vieira, J. M. F., Farias, M. F., Santos, J. L., Davim, R. M. B. \& Silva, R. A. F. (2018). Vivências de mães de bebês prematuros no contexto de espiritualidade. Rev de Pesquisa Cuidado é Fundamental Online, 7(4): 3206-3215.

World Health Organization. Preterm birth [Internet]. Geneva: WHO, updated. (2018).

Zanfolim, L. C., Cerchiari, E. A. N. \& Ganassin, F. B. H. (2018). Dificuldades vivenciadas pelas mães na hospitalização de seus bebês em Unidades Neonatais. Rev Psicologia: Ciência e Profissão: 38(1): 22-35. 